\title{
Configuration Items Selection Process Review
}

\section{Jaime Larumbe*}

Mitsubishi Heavy Industries Ltd., Tokyo, Japan

\begin{abstract}
Quick advances in technology, challenges related to globalization such as increased economic warfare among developed countries, outsourcing and offshoring, and a global over qualified and multilingual workforce are increasing the competitiveness of businesses.

In order to succeed in the rapidly evolving global manufacturing landscape, companies will need to embrace a targeted approach to some of the key elements of manufacturing competitiveness, including Configuration Management.

Configuration Management has still a long way to evolve. This study reviews the current situation of the process of Configuration Management (CM) in such a competitive world. It focuses on one of the most important disciplines within $\mathrm{CM}$, which is the Configuration Identification and more concretely the selection of Cls.

The contribution of this research is to explain: first, why CM has become more, rather than less, important in complex engineering in an era of globalization; and second, a review of the process to select the Configuration Items (Cls) which are key to manage the configuration of high tech engineering products. The investigation concludes by identifying the necessity of a scientific process for the Cls selection.
\end{abstract}

Keywords: Configuration items (CI); Configuration identification; Configuration management (CM)

\section{Introduction}

CM appeared in the United States department of defense in the 1950s as a technical management discipline for hardware material items and now is now a standard practice in virtually every industry.

This discipline was improved and implemented in the SW industry in the 80s and it was framed in Quality by the ISO 10007 in the 90s.

The discipline is specially applied in is a system whose failure or malfunction may result in one (or more) of the following outcomes:

- Death or serious injury to people

- Loss or severe damage to equipment/property

- Environmental harm.

Good examples can be found in the following sectors:

- Infrastructure

- $\quad$ Medicine

- Nuclear engineering

- Transport.

Configuration management $(\mathrm{CM})$ is a systems engineering process for establishing and maintaining consistency of a product's performance, functional, and physical attributes with its requirements, design, and operational information throughout its life. The purpose of the discipline of Configuration management is to plan, identify, control and track a products configuration during its lifecycle with minimum cost in a quick, methodical, accurate and well understood way [1].

When CM is used over the life cycle of a system, gives clarity and control of its performance, functional, and physical features. $\mathrm{CM}$ proves that a system develops as planned, and is identified and documented in detail to guide its projected life cycle. The CM discipline facilitates orderly management of system information and system changes for such beneficial purposes as to revise capability, improving performance, reliability, or maintainability; increasing life; decreasing cost, risk and liability; or amending defects (Figure 1) [2].

\section{Discipline}

$\mathrm{CM}$ highlights the functional relationship between parts, subsystems, and systems for effectively controlling system change. CM supports the verification of changes which are methodically considered to reduce negative results. Changes to the system are requested, analyzed, and implemented applying a standardized, systematic procedure that guarantees coherence, and requested changes are assessed in terms of their foreseen influence on the whole system [3].

A complete CM program holds provisions for the storing, tracking, and updating of all system information on a component, subsystem, and system basis. A structured CM program guarantees that documentation (e.g., requirements, drawings and specifications,) for items is exact and coherent with the current development of the item. During system development, CM allows program management to track requirements during the life cycle through acceptance, roll-out and maintenance [4].

As changes are unavoidably made to the requirements and design, they must be validated and documented, creating an exact record of the system situation. Typically, the CM process is implemented during the system lifecycle.

Sometimes the changes are implemented and the documentation is updated after that. This reverse engineering process is wasteful in terms of human and other resources and can be minimized or eliminated using CM. For this reason, engineers, contractors, and management

*Corresponding author: Jaime Larumbe, Mitsubishi Heavy Industries Ltd., Tokyo Japan, Tel: +97455446410; E-mail: jaime_larumbe@dohametro.mhi.co.jp

Received April 15, 2017; Accepted August 24, 2017; Published August 28, 2017

Citation: Larumbe J (2017) Configuration Items Selection Process Review. Ind Eng Manage 6: 216. doi:10.4172/2169-0316.1000216

Copyright: @ 2017 Larumbe J. This is an open-access article distributed under the terms of the Creative Commons Attribution License, which permits unrestricted use, distribution, and reproduction in any medium, provided the original author and source are credited. 


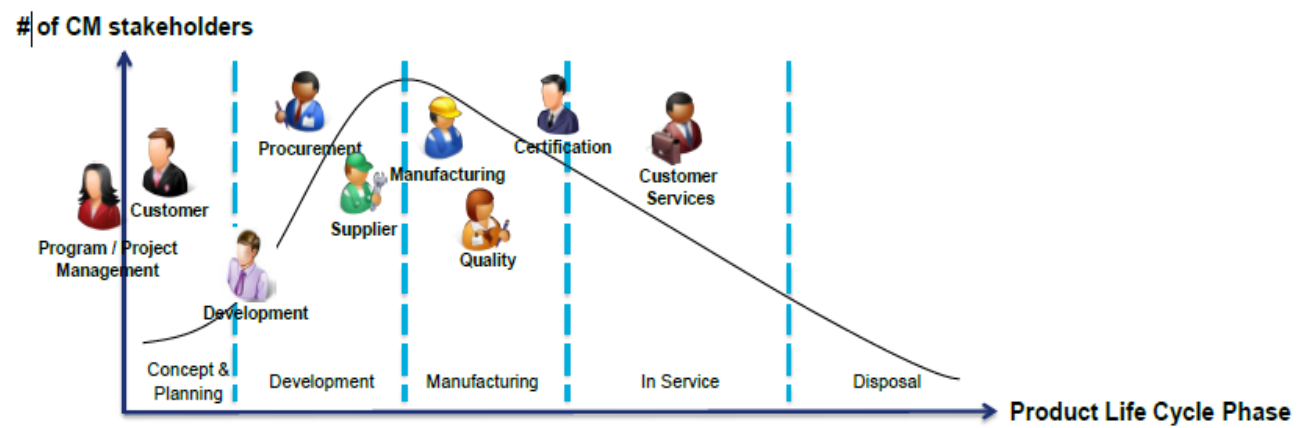

Figure 1: CM stakeholders during the product life cycle.

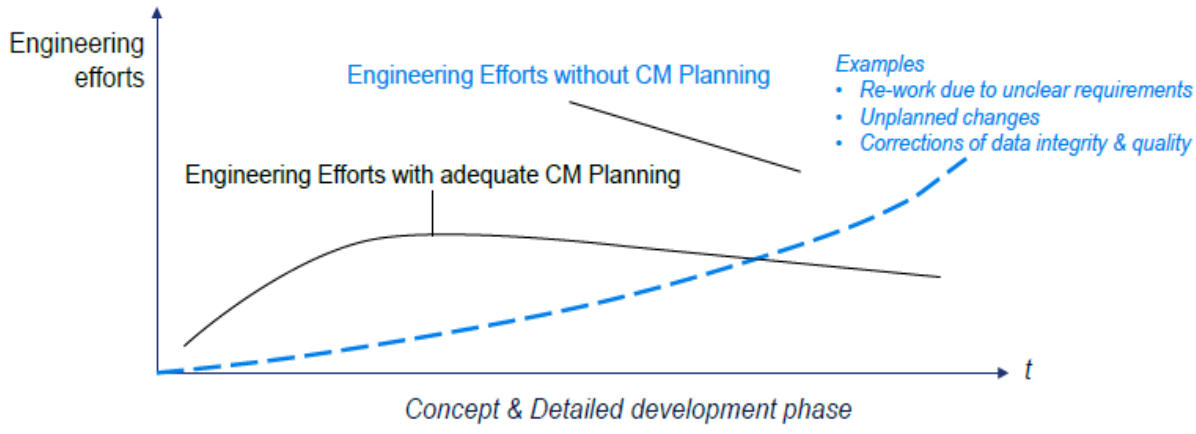

Figure 2: Engineering efforts during the concept and detailed development phase.

are usually pushed to develop documentation showing the situation of the item before they can progress with a change $[5,6]$.

The comparatively minimal cost of establishing CM is given back most of the times in cost decreasing. The lack of CM, or its incorrect establishment, can be very expensive and sometimes can have such bad results such as failure of equipment or deaths. In many cases, without $\mathrm{CM}$, the documentation exists, but is not coherent with the item itself (Figure 2).

\section{Example for insufficient change management}

Example: Volkswagen Passat, model 1991.

- Repair shop: Change of brake pads after purchase of original spare brake pads from VW dealer

- Brake pads not matching with Passat model 1991, although listed as correct

\section{Explanation}

- 4 weeks before market entry of model 1991, VW had problems with new engines

- Change: New model engine is changed to old model engine from 1989

- Affected assembly includes front axle and brakes

- Impact on spare parts of new model not identified

- No change of spare parts

The later a change takes place, the bigger the impacts and the higher the cost of change.
Consistent Configuration Management provides the basis of information for Key Performance Indicators (KPI).

They allow for a continuous monitoring with focus on e.g.:

- Change causes and classification

- Change implementation status and lead time

- Data quality

- On-time development, lead time.

KPIs can be useful to monitor the project from the beginning of a new project. As an example, KPIs could be defined for requirements management:

- Requirements cross-readings: Feasible/Not feasible requirements

- Amount and causes of requirement changes

KPIs inform about root causes of problems, support risk analyses and explain project delays.

Already in early life cycle phases KPIs are useful indicators for progress or problems.

The CM discipline for any type of configuration items whether hardware, software or firmware comprises five distinct processes $[1,6]$.

Configuration Management Plan (CMP) defines the project-related management factors, activities and information. Product and project requirements must be controlled from the beginning. $\mathrm{CM}$ integrates and links, all product-related information and activities (Figure 3). 


\section{Configuration identification}

This process is the key by which changes to any part of a system are established, classified, documented, and later tracked through design, development, testing, audit and definitive distribution. The diagram below illustrates the CM activities performed in relation to defining the documentation and product structure, aligning CIs to allocated requirements and defining baselines (Figure 4).

\section{Configuration control}

Is the exercise of operating changes systematically so that a system keeps its integrity during its lifecycle. The four-step approach is an intuitive way for dealing with changes. In general, a change process workflow covers the intuitive four-step approach (Figure 5).

\section{Configuration status accounting}

In short, it is to know where an item is in the product and how and why it got there. The reporting tasks of Configuration Status Accounting (CSA) are primarily based on the Baseline evolution along the product life cycle (Figure 6).

\section{Configuration verification and audit}

It is an independent evaluation of hardware and software for the intention of assessing fulfilment with established performance requirements, commercial and appropriate standards, and the as requested, as designed, and as produced baselines (Figure 7).

A case study in...

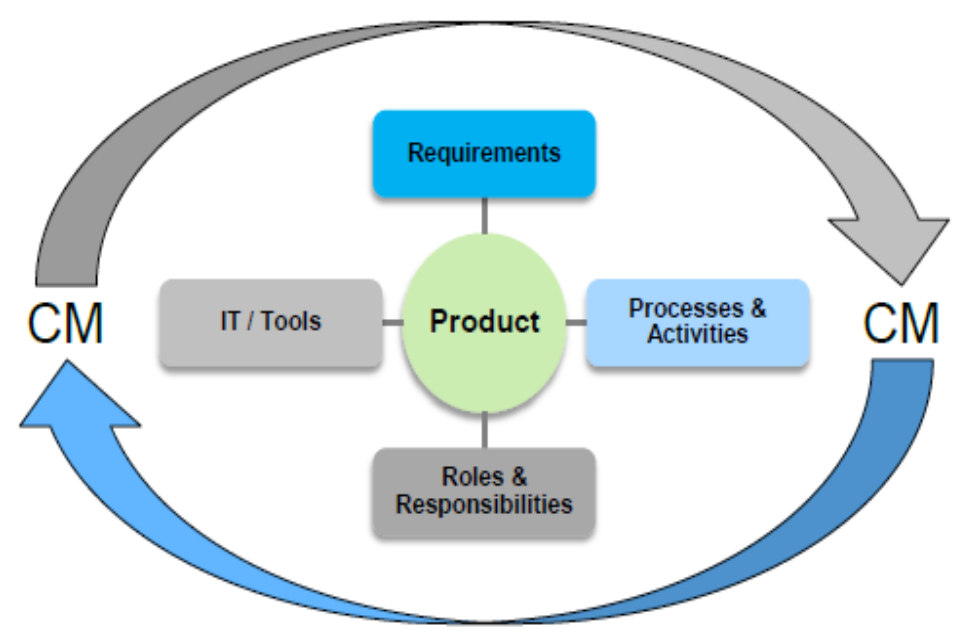

Figure 3: $\mathrm{CM}$ as a project integrator.

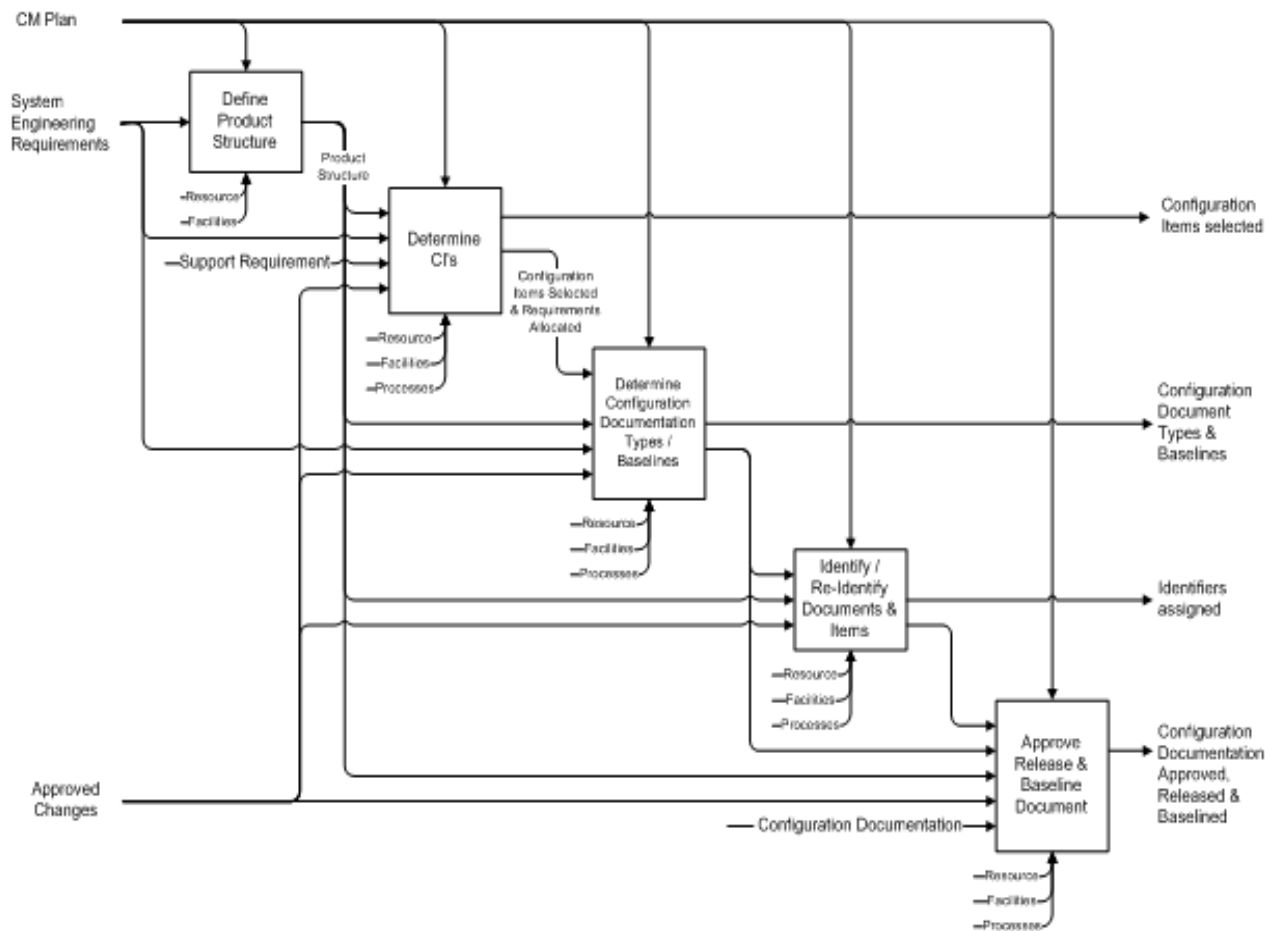

Figure 4: Configuration identification 


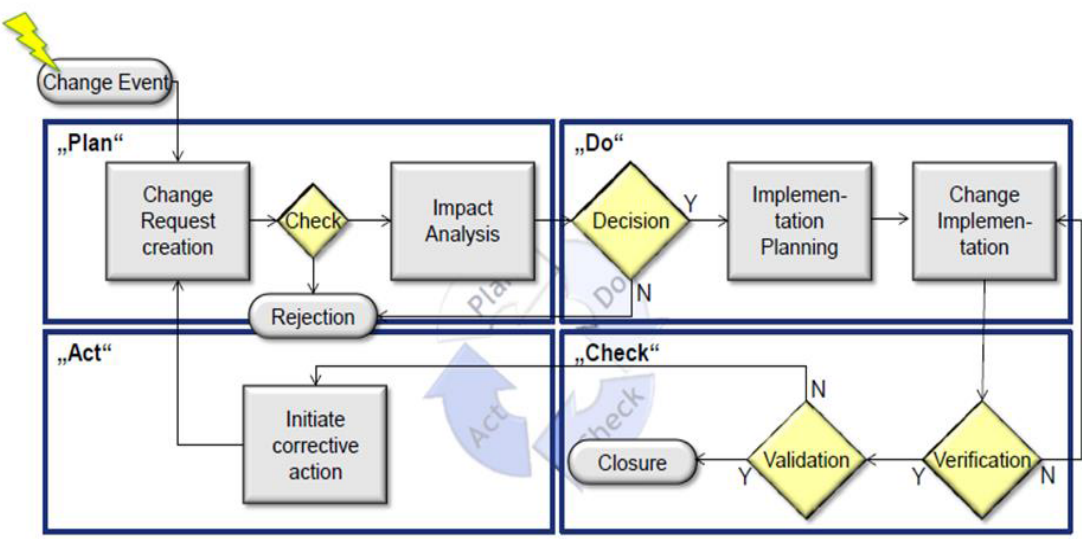

Figure 5: PDCA for configuration control.

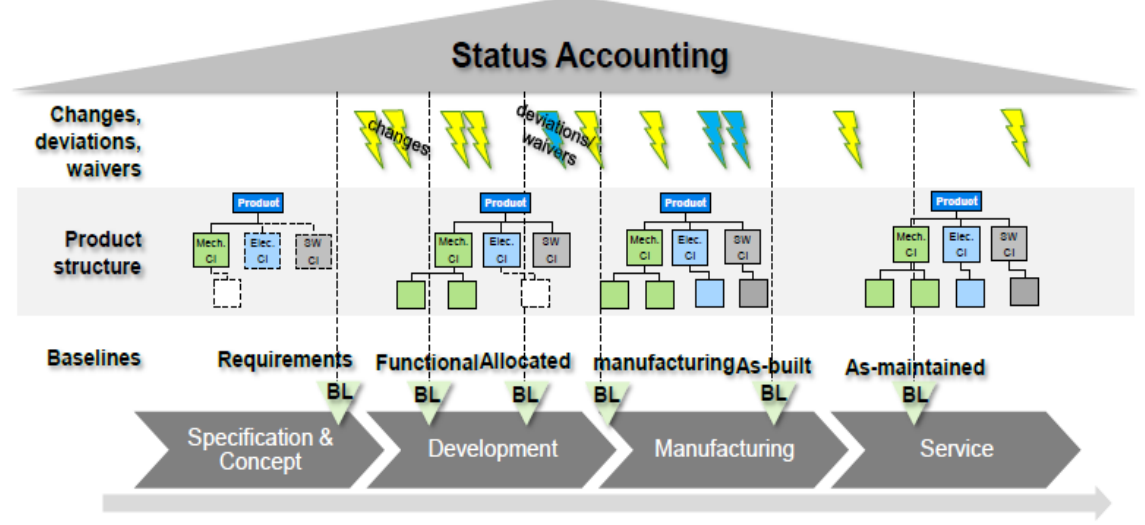

Figure 6: Configuration management status accounting.

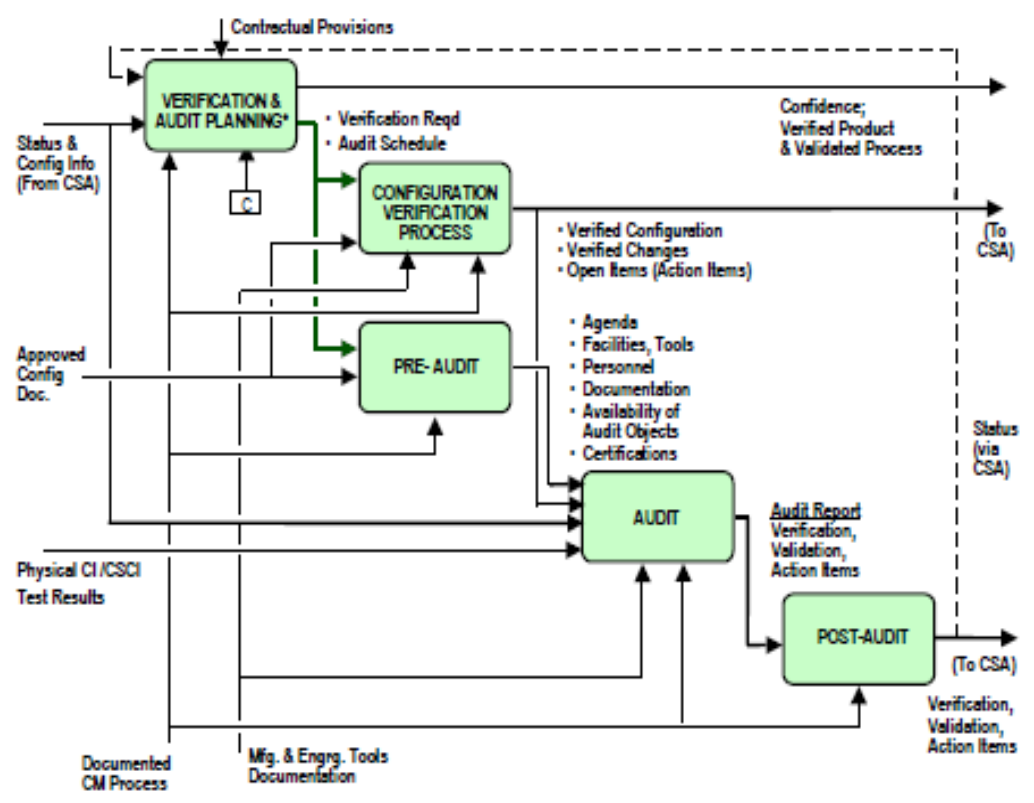

Figure 7: Configuration verification and audit activity model. 
A concrete product example (coffee maker), evolving through the different life cycle phases.

Configuration management supports the controlled management of a product throughout its life cycle (Figure 8).

Requirements management - Example: Figure 9.

Requirements finally lead to the complete product.

Different breakdowns of requirements lead to different product breakdown views.

Each product structure view features its own type of CIs. Functional or System CIs of the coffee maker could be: Figure 10.

Depending on the product structure view, different types of Configuration Items can be identified.

Each product structure view features its own type of CIs. Functional or System CIs of the coffee maker could be: Figure 11.
Depending on the product structure view, different types of Configuration Items can be identified.

Configuration Identification: Naming and Numbering (Figure 12).

Unique Numbering for all objects describing the product configuration: Physical parts, documents, software, change requests, Baselines...

The following illustration is an example for baselines. It shows one part of the coffee maker (the cup stand) and how it evolves over time (Figure 13).

Baselines can constitute both a status and a target to be reached. If the baseline is the starting point of a change, it captures a product status. If it is a target, it consists of the target data (Figure 14).

Each Configuration Baseline type comprises different content. The content of the baselines is always Configuration Items with their corresponding documentation.

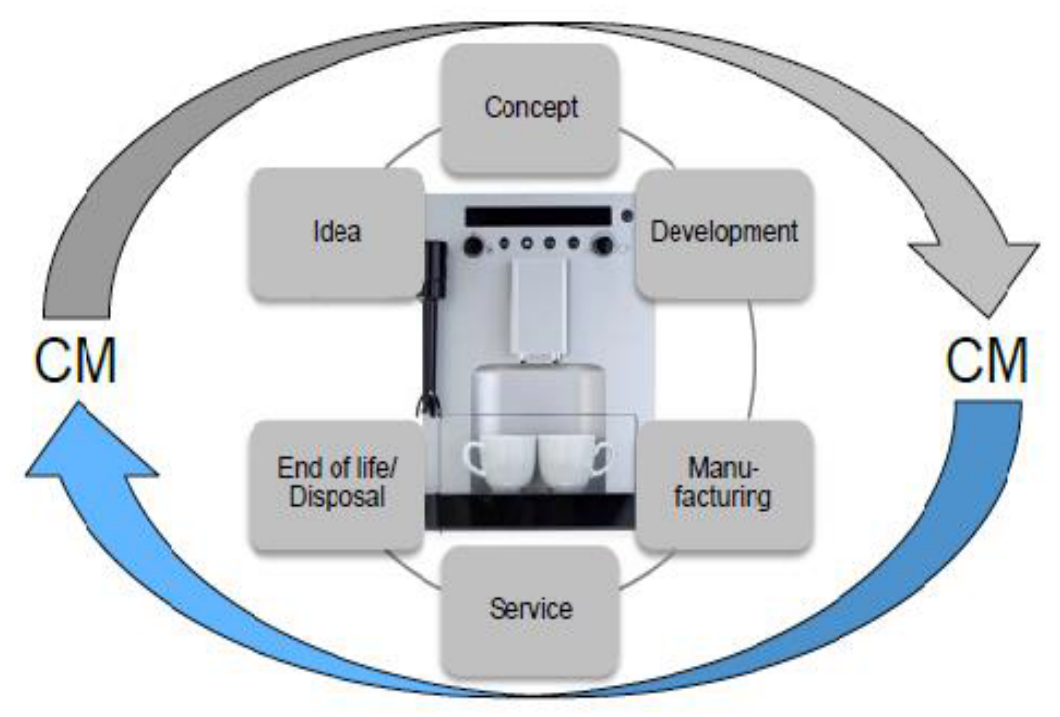

Figure 8: $\mathrm{CM}$ as an integrator of the coffee maker.

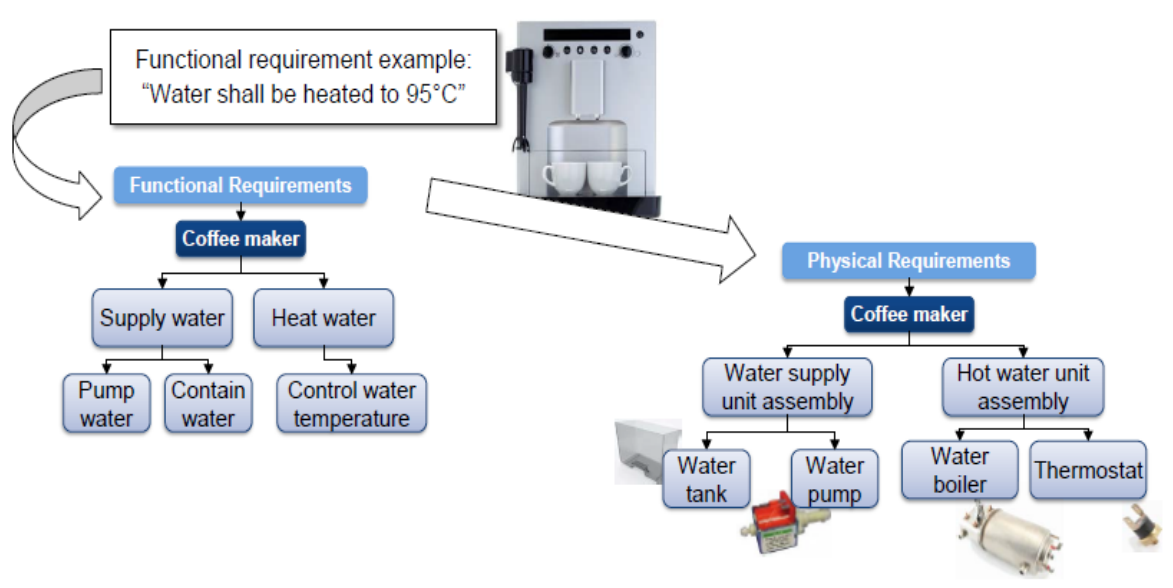

Figure 9: Requirements management for a coffee maker. 


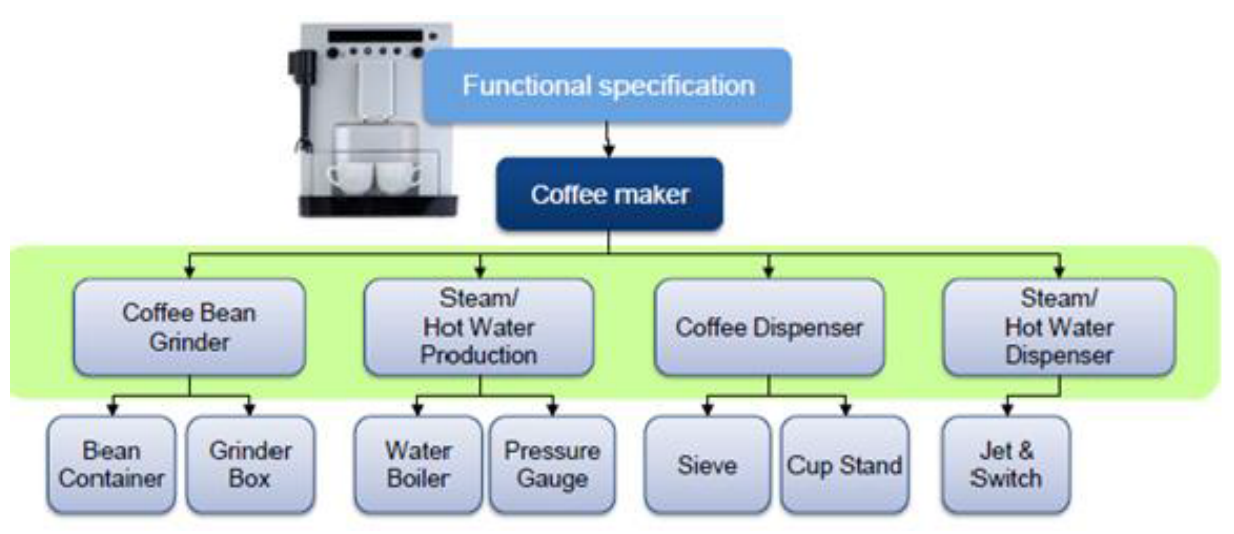

Figure 10: Functional and system Cls.

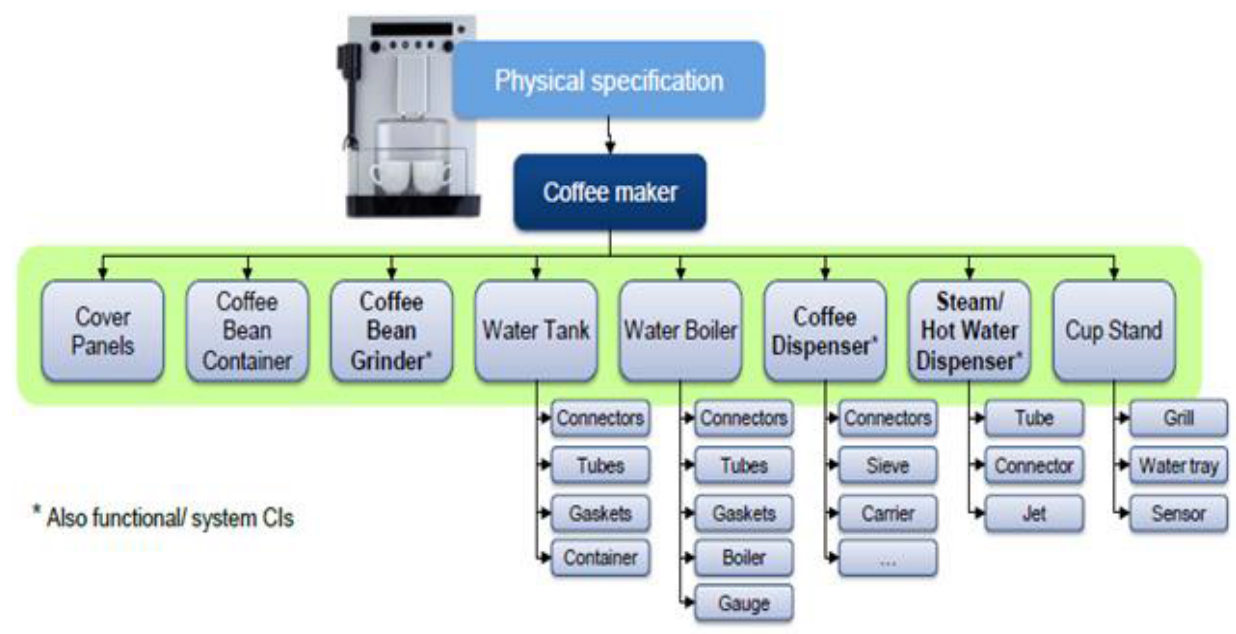

Figure 11: Physical and functional Cls.

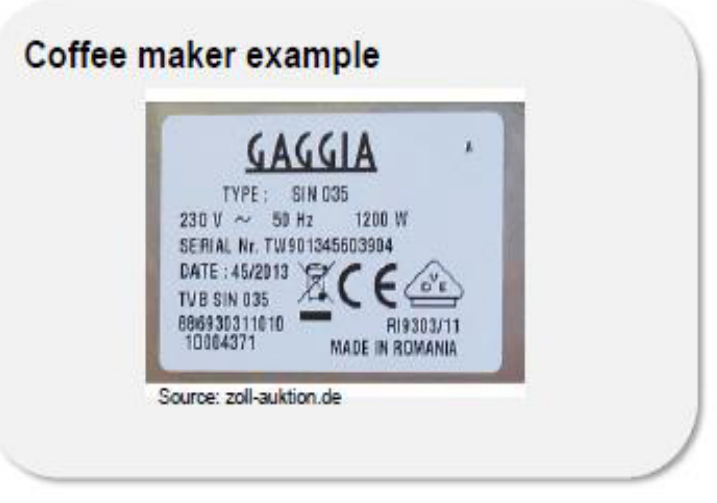

Figure 12: Label of a coffee maker.

Change Process (Figure 15).

The following changes affect the coffee maker

\section{Law: Reduce lead concentration}

"A safety study shows: Doses of lead are released into drinks after being cleaned. These doses have to be reduced due to possible risks to health."

\section{Market: Use tall cups/glasses}

"A market study shows: End users would like to use a broader range of cups and glasses, e.g. for tall latte macchiato."

\section{$R \& D^{\star}$ : Improved milk foam unit}

"R\&D proposes an improved milk foam unit which is easier to clean and produces finer foam."

\section{Change impact analysis - coffee maker process}

The change impact analysis is "the heart" of the change process: All impacts of a change shall be considered in order to prepare the implementation decision (Figure 16).

Reports related to Baseline evolution - Example (Figure 17).

\section{Manufacturing - Configuration audits and conformity}

Overall understanding: Configuration Conformity documents whether a built product differs from its requirements, functional and physical specifications (Figure 18). Configuration Conformity means that a product meets all physical and functional requirements. 


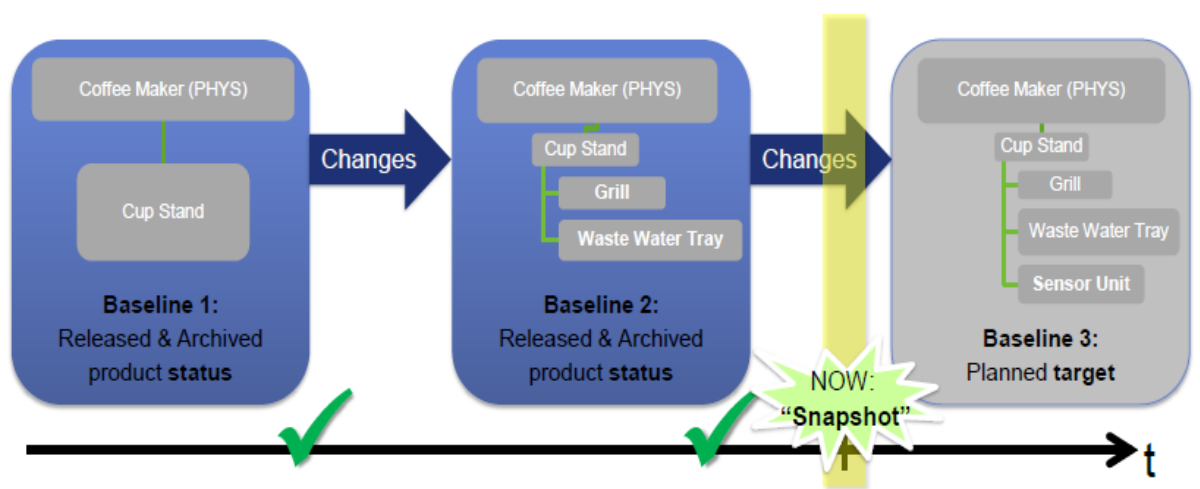

Figure 13: Baselining in a coffee maker.

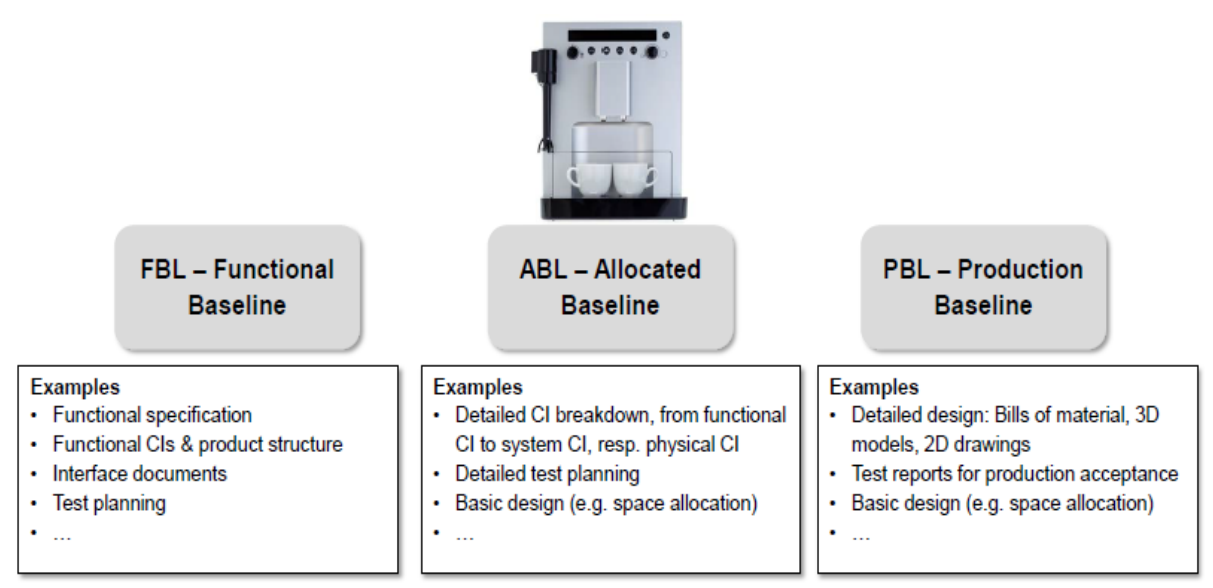

Figure 14: Examples of baselines in a coffee maker.

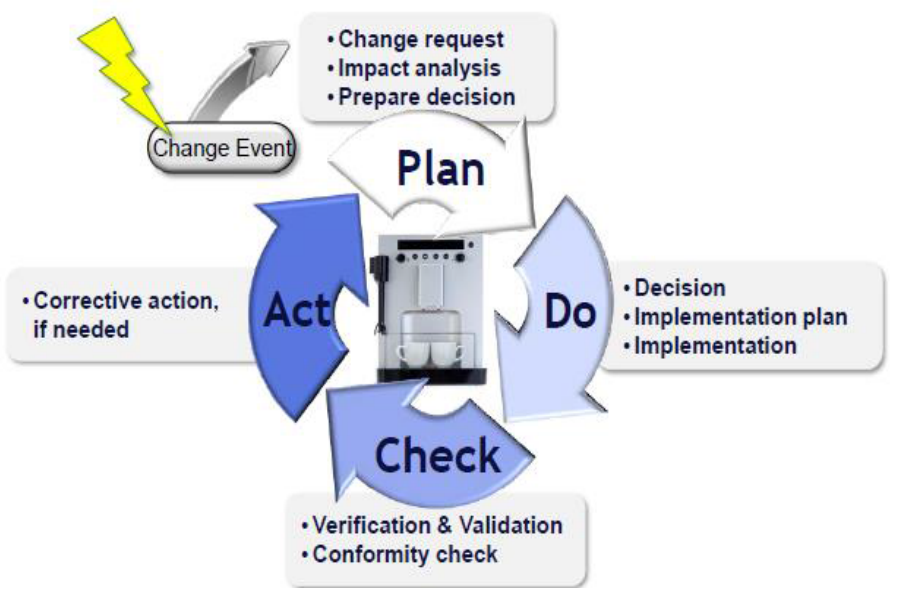

Figure 15: PDCA for the change process in a coffee maker.

\section{Configuration identification}

Configuration Identification is the activity to uniquely identify and document functional and physical characteristics and interrelationships of a selected item, so that it can be later achieved in a product. The activity is a prerequisite to creation of baselines identifying the system, subsystem and elements of each $\mathrm{CI}$ at a given point in time, as such enabling CM Status Accounting, Audit, etc. [3]
If CIs and their associated documentation are not properly identified, it is impossible to control change, establish accurate records, and to report and validate through audit. CM shall ensure all CIs, or any part thereof, and associated supporting items are each designated a unique identity, consisting of numbers, letters, symbols, or combination thereof [7].

Unique identification shall be guaranteed, and shall encompass 


\begin{tabular}{|ll|}
\hline Impact & Description \\
\hline Affected products & $\begin{array}{l}\text { - New coffee maker model in development } \\
\text { - (Retro-fit for delivered models in-service (optional)) }\end{array}$ \\
\hline $\begin{array}{l}\text { Affected baselines \& } \\
\text { product data }\end{array}$ & $\begin{array}{l}\text { - Functional/ Requirements Baseline, Allocated Baseline, Design } \\
\text { Baseline, Built/ Delivered Baseline } \\
\text {-3D, 2D, Software, Manufacturing instructions, Maintenance manual }\end{array}$ \\
\hline Affected stakeholders & $\begin{array}{l}\text { - Internal: Mechanical Engineering, Electrical Engineering, Software } \\
\text { Engineering, Manufacturing, Logistics (stock), Customer Service (spares), } \\
\text { Sales } \\
\text {-External: Design suppliers, Part suppliers, Customers }\end{array}$ \\
\hline Impact on cost & $\begin{array}{l}\text {-NRC*: Design \& development effort, Manufacturing \& Maintenance tools } \\
\text {-RC: Supplied parts }\end{array}$ \\
\hline Impact on sales & $\begin{array}{c}\text { - "Unique Selling Point"- best milk foam unit in the market } \\
\text { - Customers are willing to pay a higher price }\end{array}$ \\
\hline Impact on schedule & \begin{tabular}{l}
-. \\
\hline
\end{tabular} \\
\hline
\end{tabular}

Figure 16: Change impact analysis for a coffee maker.

\begin{tabular}{|c|c|c|}
\hline Who? & Which Information? & When? \\
\hline Engineering & $\begin{array}{l}\text { - Requirements Baseline } \\
\text { - Valid set of requirements \& } \mathrm{Cl} \text { : } \\
\text { Functional/ Allocated Baseline }\end{array}$ & - Concept phase \\
\hline $\begin{array}{l}\text { Procurement/ } \\
\text { Supplier }\end{array}$ & $\begin{array}{l}\text { - Valid set of requirements \& } \mathrm{Cl} \text { : } \\
\text { Functional/ Allocated Baseline } \\
\text { - Identified Long Lead Items }\end{array}$ & - Development phase \\
\hline Manufacturing & $\begin{array}{l}\text { - Master Design: Design Baseline } \\
\text { - Test reports (manufacturing readiness) } \\
\text { - Changes affecting manufacturing }\end{array}$ & - Latest: Design Freeze \\
\hline Quality & $\begin{array}{l}\text { - Master Design: Design Baseline } \\
\text { - Test reports } \\
\text { - Change status: incorporated or in-work }\end{array}$ & $\begin{array}{l}\text { - Latest: Start of } \\
\text { manufacturing }\end{array}$ \\
\hline $\begin{array}{l}\text { Programme } \\
\text { Management }\end{array}$ & $\begin{array}{l}\text { Valid set of contractual requirements: } \\
\text { Requirements Baseline } \\
\text { Change status: causes, cost, implementation }\end{array}$ & - From project start \\
\hline $\begin{array}{l}\text { Customer } \\
\text { Service }\end{array}$ & $\begin{array}{l}\text { - Master Design: Design Baseline } \\
\text { - Changes affecting in-service models }\end{array}$ & $\begin{array}{l}\text { - Latest: Start of } \\
\text { manufacturing }\end{array}$ \\
\hline
\end{tabular}

Figure 17: Reports related to baseline evolution.

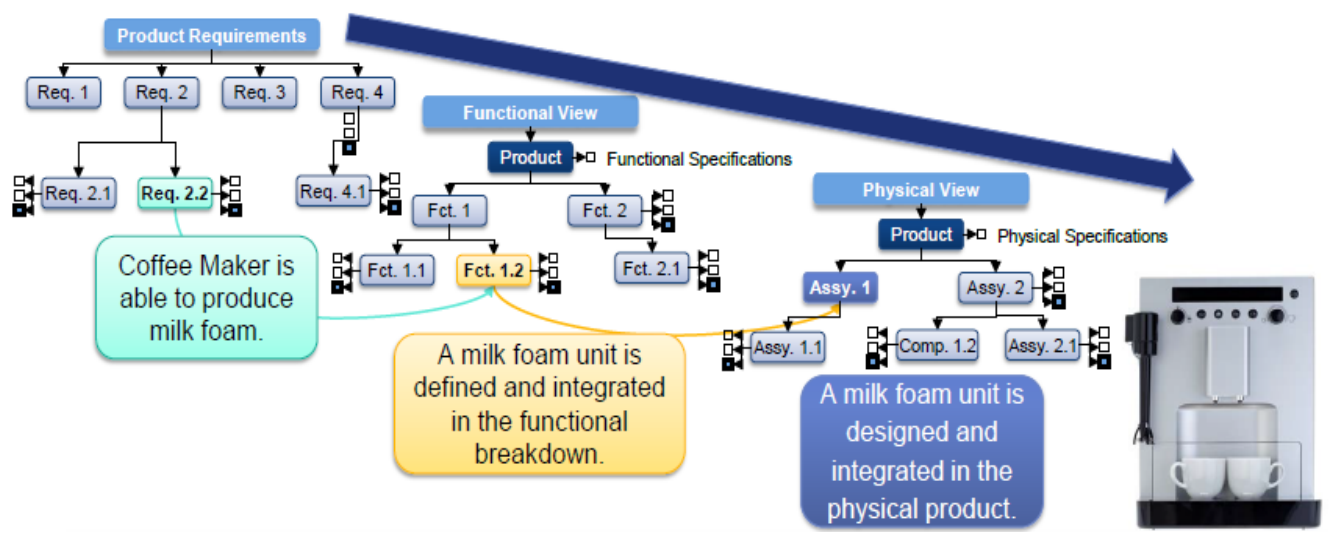

Figure 18: Configuration Conformity for a coffee maker.

the ability to control differing external numbering schemes. It may be desirable to reserve a reference sequence range for a specific usage (e.g. project phase or specific product, partner sharing needs), blocked for usage by other projects. According to the type of the CI the labelling can be either physical e.g. labels on hardware or headers inside software, where existing CI are reused the original identification shall be maintained [8].

With the help of the part number (PN) all products, parts and parts lists will be identified unique. The "significant" number enables the 
user to find also other parts or products, which are in relationship with the desired part or product (Figure 19).

Configuration Management shall allocate a unique identifier (consisting of numbers, letters or symbols, or combination thereof), to uniquely identify the $\mathrm{CI}$, and cross-reference to other drawings or documents as appropriate, subsequently recording in the project specific 'Documentation Plan'. All documentation defined as CIs, and any supporting documentation derived from CIs, shall for release be distinguished by the application of issue numbers. Any deviation away from this standard shall be documented in the associated project CM Plan [9].

Changes to documentation during the creation cycle, up to the point of release, will be tracked within using content versions. Documentation is controlled by means of a record to which the original file is attached. Legacy projects, when imported into a software management tool may have documentation identified automatically, however, until such a time as a project agrees to adopt automated identification only, a facility shall be available to manually assign a legacy number in accordance with the project CM Plan [10].

Bespoke Hardware CIs shall be uniquely identified, this will be the design reference, and will only change when design changes affect interchange ability of the part (Form, Fit or Function change). All HWCIs, or aggregated HWCIs, forming a subsystem or system shall be identified, establishing information permitting baseline declarations to provide assurance of certification. Computer Software Configuration Items (CSCIs) shall be uniquely identified, including all instructions/ data, operating systems, supervisory systems, compilers and test routines as well as application programs. Software control shall be via a version management tool, with change history and versions tracking changes made to each file, giving the ability to retrieve any version of a file at any future date [3].

Definition of CI: A Configuration Item (CI) can be defined as an item whose changes are controlled, which is subject to review and authorization, with $\mathrm{CM}$ applying version control and maintenance through a Product Lifecycle. CIs are the essential entities of configuration management. It may be a single part or line of software code or an assembly of parts of a whole software program or any compilation of them [11].

They might vary a lot in complexity, size and type, from an aircraft, train, or tank, to an electronic system or software program. Aside of form, size or complexity, the configuration of a $\mathrm{CI}$ is documented and controlled. CI selection separates system components into traceable subsets for the intention of managing additional development [12].

A Product Structure and the tools in which it is implemented serves the purpose of sharing product information qacross multiple functions and the corresponding stakeholders (Figure 20).

Product structure and related tools are the backbone to provide and share consistent product information as basis for the work of multiple functions and stakeholders along the product life cycle.

For each and every CI there will be associated configuration documentation, Configuration changes will be controlled, Configuration status accounting records will be maintained and Configuration audits will be addressed to check performance and product configuration. Furthermore, physical and functional interfaces

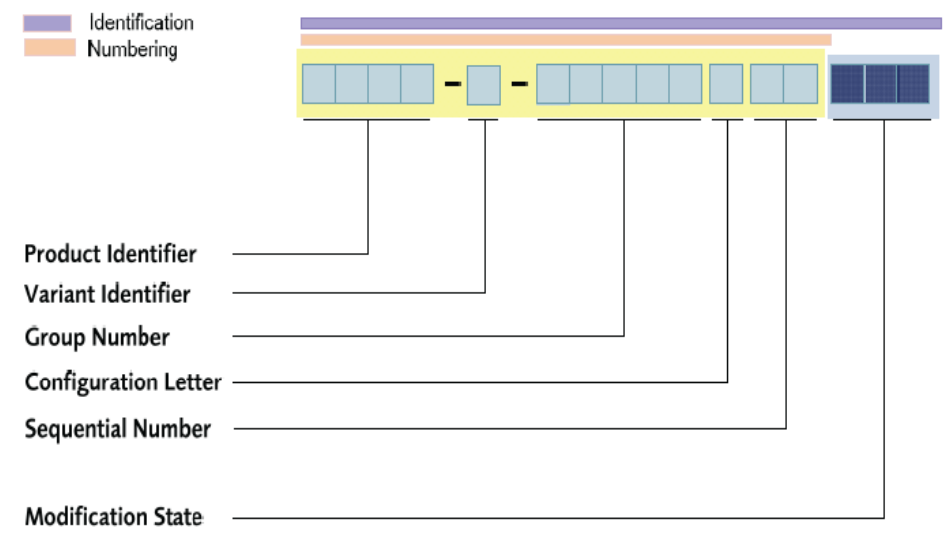

Figure 19: Item identification.

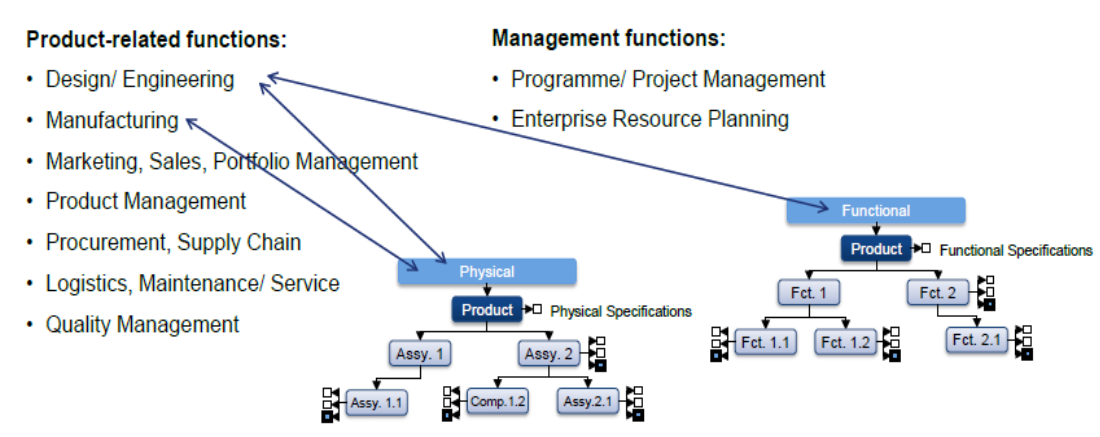

Figure 20: Physical and functional structure. 
of the system, equipment, software, facilities, installation, and external systems shall all be precisely controlled via documentation [13].

Just because a CI has to be controlled, does not imply that all of its hardware and software components must be selected as CIs, nor does it imply that the performance requirements for the items which are not designated as CI must be under customer control. The requirements to be met by these items are established and controlled by the Contractor's design and engineering release process. Customer control happens just when changes to the lower level components impact the customer approved baselined performance specification for the CI [14].

\section{An example of an item affecting to a $\mathrm{CI}$ is the following:}

Recall of 4.2 million Toyota and Lexus vehicles because floor mats could jam the gas pedal down.

Toyota changed during the development process the floors mats without taking in account the impact in all of the CIs, in this case the gas pedal, and the result was that once that the car was in service, the floor mats could jam the gas pedal down.

As a result, the cost of change was:

- Cost of spare parts, w/o labor cost: 120 million \$

- Cost of claims and legal charges: $\sim 1.7$ billion $\$$

In the beginning of the acquisition, for Engineering and Manufacturing Development, CIs normally are the deliverable and separately installable entities of the system and other items requesting, relevant management consideration at customer/supplier interfaces. All along Production, roll-out/Deployment and Operational Support, single items required for logistics support and identified for separate procurement are also CIs [11].

As a conclusion, CI selection identifies the degree of configuration control throughout the system life cycle (Figure 21).

\section{Rules for selecting CIs}

The CI selection should be achieved by a panel of authorized personnel reviewing the Product Break-down Structure (PBS), and Document Structure, considering the selection attributes identified above, with $\mathrm{CM}$ recording the candidate items and allocating appropriate identification [15].
Every CI should identify a different entity that implements at least one end use function. The selection of CIs should reflect a high degree of independence among the CIs at the same level. However, subordinate components, which are recommended as CIs during the detail design process, should all be functionally interrelated [1].

All subassemblies of a CI should have common function, installation and deployment requirements. Identifying a system component as a CI improves the clarity and control throughout the development. Therefore, for critical systems or high technical risk components, added clarity can help in meeting some milestones [16].

On the other hand, major functional design components are usually designated as CIs in complicated systems. The first selection is usually the major component level of the product breakdown structure. As system develops and complex items are further subdivided into their components, additional CIs might be selected [11].

Computer software items are almost always designated as CIs because they typically control the functionality of a system. Apart from that, operational software should always be differentiated from support software by selecting each as a separate CI. The complexity of CI interfaces in a system should be minimized, since complexity often results in increased risk and cost [15].

For systems with common components, subsystems, or support equipment, each common item should be separately designated as a $\mathrm{CI}$ at an assembly level common to both systems. If a component is unique to only one of multiple similar systems, this component should be identified as a separate CI of that system [17].

Unless the commercially available items had been modified at customer expense, Commercial Off-the-shelf (COTS) privately developed items usually should not be identified as CIs. If this is the case factors to consider include:

- Extent of the modification

- Criticality of the modified CI to the mission of the system

- Extent of ownership, data rights, and configuration documentation required and available to the customer.

Finally, any COTS identified for logistic support by the customer should be selected as a CI. In such cases, the customer must collect

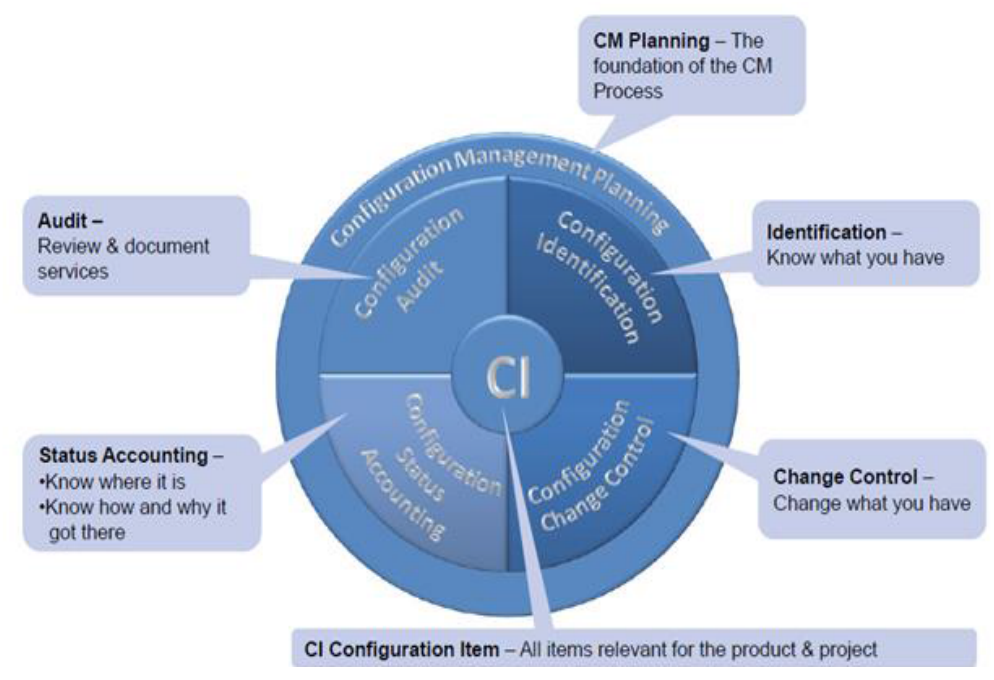

Figure 21: Configuration management - Overview. 
enough configuration documentation to permit the support.

\section{Results of the Questionnaire}

From the set of personal questions, it can be highlighted the fact that all the people involved have wide experience in the area of Configuration Management, as it can be observed in the following chart:

The importance of the process of selecting CIs can be derived from the following question where all the surveyed answered that they had taken part in the process.

The technical side starts with a result already intuited. Unanimously, all participants agree on the importance of the selection process of the CIs.

As it can be observed in the following chart, in general all of the experts recognize that all the CIs have to be serialized in order to be unequivocally traced.

Regarding the standards or instructions that are followed to select them, there is diversity. Some of them recognize relying on defense standards like MIL-HDBK-61A and another in civil standards like ANSI/EIA-649B.

In no case, any of them provides a new documentation to support the process.

About the problems derived from an inappropriate selection, they provide a lot of new ideas apart from recognizing the problems identified in the questionnaire:

- Wrong change implementation

- Change defects

- Redeployment

- Data not maintained

- System not used.

On the other hand, there is no unanimity in the department or areas of knowledge that should be involved in the process; CM and Engineering are the most recurrent, but there are also other areas mentioned like Production, Maintenance, Integrated Logistic Support..

There is no agreement in the fact of involving the customer in the process of selecting the CIs.

Apart from that, most of the experts appear to have a small amount of items in mind before doing the selection independently of the sector, product or customer.

In spite of recognizing unanimously the relevance of the CIs, nobody provides any flowchart, instruction, algorithm to be followed for the selection process.

A result that can be foreseen after reading the answers to this question is that in spite of the importance that the surveyed give to the selection process it has to be recognized that it has an intuitive nature.

One more time the consensus is met in the following question where the vast majority of the participants recognize the attributes introduced in the questionnaire.

Besides of those attributes, budget and time are new proposals almost by unanimity.
According to the answers the factors are supposed to have the same weight and the as required is not recognized unanimously as something to be considered during the selection process.

The requirements seem to have the same weight according to the majority and the as designed baseline is not recognized for the process either.

There is lack of agreement in the following question, just a slight tendency to place the process after the as designed baseline.

The importance of time and budget are identified as important factors to be considered in the process by the vast majority of experts.

Almost impossible to get consensus among the stakeholders involved in the selection process according to the surveyed CM colleagues.

Again a contradictory idea since although the surveyed recognize the lack of CM expertise of the customers, they assure that the final approval comes from the customer.

Diversity again in this case about how to evaluate the accuracy of the selection. There is no clear key performance indicator (KPI).

Some of participants did a new proposal of CIs after the approval and some of them introduced Cis proposed by the customer in spite of not meeting the attributes that all the CIS have to meet.

\section{Conclusions}

The main objective of this study is to review the CM discipline and to identify possible gaps in order to increase the competitiveness of high tech product manufacturers in such a key sector for the economy of any country.

The discipline has been explained by a simple example, but containing all processes necessary for proper implementation of the CM.

A questionnaire has been created to benchmark the discipline in order to obtain information to help organizations to improve the CM.

The questionnaire will help CM practitioners think and communicate their expertise about some of the most common and important points.

Experienced $\mathrm{CM}$ professionals were involved to ensure the usefulness and effectiveness of the study.

This study identifies the importance of an accurate selection of CIs for the effective implementation of $\mathrm{CM}$ in high tech product manufacturers based on the views of experienced CM practitioners.

Significant similarity is found in the CM practitioner's perception on the attributes suitable to select the CIs.

In spite of that, emphasis is made to reveal the lack of a scientific approach to select the CIs independently of practitioner's academic qualification, work experience, CM certification/training, and experience in stakeholders' departments.

This research contributes to existing knowledge by identifying the necessity of a scientific approach to select the CIs as a necessary step for the effective implementation of CM within high tech industry.

\section{References}

1. TechAmerica (2012) ANSI/EIA-649B, National Consensus Satandard for Configuration Management. SAE International, p: 85

2. Rachuri S, Foufou S, Kemmerer SJ (2006) Analysis of Standards for Lifecycle 
Managementt of Systems for US Army. National Institute of Standards Technology for Lifecycle Management of Systems for US Army. NISTIR 7339

3. Buckley FJ (1993) Implementing Configuration Management: hardware, software and firmware. IEEE Computer Society Press, p: 380

4. Defense Acquisition University (2012) Systems Engineering Fundamentals.

5. Federal Transoportation Adminstration (2007) Configuration Management, National Learned Program.

6. Department of Defense (2012) MIL-HDBK-61A, Military Handbook: Configuration Management Guidance.

7. Ali U, Kidd C (2013) Critical success factors for configuration management implementation. Industrial Management \& Data Systems.

8. Berlack, Ronald H (1992) Software configuration management.

9. Wu WH (2012) A novel CMIl-based engineering change management framework: an example in Taiwan's motorcycle industry IEEE Transactions on Engineering Management 59: 494-505.

10. Bellovin S, Bush R (2009) Configuration Management and security. IEEE Journal on Selected Areas in Communications 27: 268-274.
11. Lueninghoener C (2012) Getting Started with Configuration Management login: The Usenix Magazine 36: 12-17.

12. Federal Highway Administration (2012) Configuration Management for Transportation Management Systems Handbook.

13. Burgess TF, McKee D, Kidd C (2005) Configuration management in the aeroespace industry: a review of industry practice. International Journal of Operations \& Production Management, Vol. 25: 290-301.

14. PACO Technologies Inc. (2012) Configuration Management Case Study.

15. Center Defense Technical Information (2001) Configuration Management Compliance Validation: Critial Review and Technology Assessment (CR/TA) Report.

16. Patrinostro, Frank S (1992) Software configuration management: identification, accounting, control and management. McGraw-Hill Software Engineering Series.

17. Niknam M, Bonnal P, Ovtcharova J (2013) Configuration management maturity in scientific facilities. International Journal of Advanced Robotic Systems 10: 404-409. 